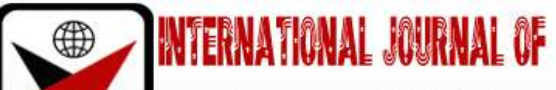

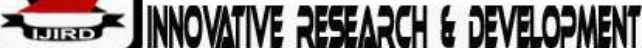

ISSN 2278-0211 (Online)

\section{Pearl Millet- Maize Substitution, Reasons for Occurrence and Economic Implications: Case of Tigania West District, Kenya}

\begin{tabular}{c}
\hline Victor Mugambi Akwalu \\
Lecturer, Department of Business Management, \\
Meru University of Science and Technology, Kenya \\
Gideon. A. Obare \\
Professor, Department of Agricultural Economics and Business Management, \\
Egerton University, Kenya \\
Bernard. K. Njehia \\
Professor, Department of Agribusiness Management and Trade, \\
Kenyatta University, Kenya
\end{tabular}

\section{Abstract:}

Pearl millet, an earlier major staple food crop in parts of Meru, has gradually faced neglect and abandonment to the point of complete abandonment. Pearl millet is highly adapted to the biophysical factors in Tigania west district and this makes it better placed and more fitting crop for the district. However, with time households have entirely shifted to growing maize as a substitute to pearl millet to the point of complete substitution. This study aimed at identifying and analyzing the factors that have led to pearl millet abandonment by farmers in Tigania West District and the consequential economic implications. Tharaka district which currently grows pearl millet was used in drawing a profitability comparison between maize and pearl millet crop enterprises. A sample of 160 farmers was selected from the population of small-scale farmers in the district. Both Primary and secondary data were collected through administration of a structured questionnaire and extensive literature review respectively. Descriptive statistics and gross margin analysis were applied in analysis and interpretation of results.Levene's test for equality of variances and t-test for equality of means was carried to establish the equality of variances and mean gross margins for the two samples. The results indicate that 62.5 percent of the respondents substituted pearl millet for maize due maize's flexibility attribute. Pearl millet was abandoned mainly due to its labor intensiveness (95 percent of the respondents) particularly during its last phase of growth when birds invade pearl millet fields. The study results indicate that pearl millet is much more profitable than maize (pearl millet gross margin is KES 498,980 while maize gross margin is KES 15,118)

Keywords: Abandonment, gross margin

\section{Introduction}

Kenya' economy largely depends on the agricultural sector, which accounted for $24 \%$ of the GDP in 2003. Majority of Kenyans (about 75\%) owe their livelihood to agriculture. Agriculture sector supports wide range of manufacturing industries, with food processing being the largest single beneficiary activity. Due to the country's agricultural economic foundation, about $66 \%$ of the manufacturing sector is agro based. (MoA, 2003). The agro-grain processing sub sector in Kenya is one of the leading and well-established industries. It includes major cereal crops such as maize, wheat, rice, sorghum, millet and barley.

Statistics indicate that pearl millet constitutes 50 percent of the total millet grain production, 30 percent comprises proso/golden and fox tail millet while 10 percent comprises finger millet. The remaining 8 species of millet are of little economic importance since they only account for 10 percent of the total world millet production (MoA, 2003). According to the Syngenta Foundation for Sustainable Agriculture, 2002, Pearlmillet(Pennisetum glaucum (L) R. Br.) is one of the top four most important cereals (rice, maize, sorghum and millets) which is grown in the tropics.

In Africa 15 million hectares of land is estimated to be under pearl millet cultivation annually while Asia has an estimate of 14 million hectares under pearl millet cultivation annually. World production of pearl millet exceeds 10 million tons a year (National Research Council, 1996).

Millet production in Kenya is mainly for domestic consumption. The types of millet varieties grown include hulrush foxtail finoer and nroen Millet nroduction in Kenva in the 2002 seacen was ectimated at 50 nกn Metric Tone 
from 115,000 hectares. Key areas growing millet in Kenya include Central, Western, South Rift and Eastern parts of Kenya (MoA, 2003).

Figure 1 depicts the millet production trend in Kenya from the year 1960 to 2009. It is apparent that the millet production in the country has been on a decline trend since 1977 to date. During 1960s millet production in Kenya was high with the highest production made in the year 1961 of 394,000 metric tons. Kenya recorded the lowest yields in millet production in the year 1984 with only 21,000 metric tonnes. Since 1982 millet production in Kenya has been below the 100,000 metric tonnes mark. Millet production in the country is characterized by variability in production but for the last four years (2006 to 2009) the production has stagnated at 70,000 metric tonnes.

\subsection{Millet Production in Kenya}

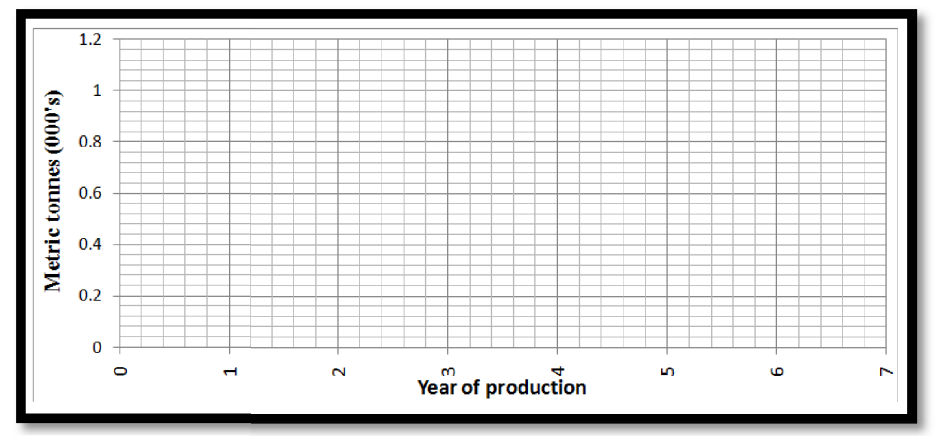

Figure 1: Millet Production in Kenya

Pearl millet has an advantage over other cereals as it can and is grown in marginal agricultural areas characterized by annual variability in rainfall. In these areas, rainfall is unpredictable and very low (200-500 mm) and daily temperatures are in excess of $30^{\circ} \mathrm{C}$ (ICRISAT and FAO, 1996). Moreover, pearl millet's nutrient content and properties are equivalent or even superior to those of other cereals (Obilana and Manyasa, 2002).

\section{Materials and Methods}

\subsection{Study Area}

The study was done in Tigania west district and Tharaka district between the months of July and October 2010. Tigania west district was selected because there has been absolute pearl millet abandonment in the district. Tharaka district which has identical biophysical factors to those in Tigania West district and which currently has pearl millet as its major crop was used to draw a comparison between economic profitability of pearl millet in tharaka district and maize in Tigania west district. Initially pearl millet used to be the major crop grown in Tigania West and during those periods incidences of food insecurity were rare. Tigania West District is situated on the western side of former Meru North district down the slopes of Nyambene ranges. The district covers an area of $386 \mathrm{sq} \mathrm{km}$ with a population of 125,000. It comprises of four administrative divisions, namely Akithi, Tigania West, Mituntu and Uringu. The district is relatively agriculturally potential, with the major economic activity being agriculture and livestock rearing. The rainfall received in the division is bimodal in nature being received in March/May and October/December. The division receives precipitation ranging from 800-1000mm per annum. Long rains are experienced in October-December while short rains in March to May. The district is generally classified as semi-arid. Tharaka district shares common borders with Meru Central District to the north, Meru North District to northeast, Mwingi District to the southeast, Mbeere District to the south and Meru south District to the east. The District is divided into three (3) administrative divisions, namely Tharaka south, Tharaka central and Tharaka north. The district has twenty (20) locations, and a total of thirty-seven (37) sub-locations. The district covers an area of $1569.5 \mathrm{~km}^{2}$ with a total population of 100,992 people (1999, Population and housing census).

\subsection{Data and Sampling Design}

A sample of 160 farmers was selected from the population of the small-scale farmers in the two districts. A sample of 90 and 70 respondents was selected in Tigania West and Tharaka districts respectively based on their population differentials. Primary data were obtained through administration of a structured questionnaire to the respondents. Multistage sampling methodology was applied. Tigania west district and Tharaka district were purposively selected due to absolute pearl millet abandonment characteristics for Tigania West district and presence of pearl millet as the major crop in Tharaka district. Three divisions (Akithi, Mituntu and Uringu) were randomly selected in Tigania west district and all the three divisions (Tharaka south, Tharaka central and Tharaka north) were selected in Tharaka district. From each division two locations were randomly selected. Simple random sampling was applied in selecting 160 small scale farmers on a proportionate to size basis.

\subsection{Analysis}

This study was informed by the theory ofinter-seasonal dynamic utility optimization model. The theory postulates that crop abandonment decisions usually occur during the growing seasons as a response to expectations of 
changes in yields and prices (Chambers 1989; Horowitz et al 1993; Vercammen et al 1994; Babcock et al 1996; Coble et al. 1997; Chambers et al 2002). Therefore, to clearly elucidate a farmer's crop abandonment decision a theoretical interseasonal dynamic utility optimization model has to be constructed. This theory rests on the assumption that the producer's objective is to maximize the expected net profit and eventually net utility at harvest. This theory allows a farmer to re-evaluate the price and yield expectations for the successive season based on the outcome of the preceding season, to decide whether to abandon the crop. In this scenario, we consider a farmer whose goal is to maximize expected net profit realized at harvest time. The crop growing period is therefore divided into seasons: season 1 , which begins at time $t=0$ and ends at $t=1$, and season 2 , which begins at $t=1$ and ends at $t=2$ all the way to season $\mathrm{n}$ which begins at $t=n-1$ and ends at $t=n$. At $t=0$, the farmer evaluates the previous season's net utility derived from pearl millet cultivation. The farmer then uses the previous season's net utility to draw an estimate of the successive season's expected net utility. If the expected net utility (ENU) is less than the previous season's net utility derived (NUD) the farmer decides to abandon the crop at timet $=1$. However, if the ENU is greater than NUD the farmer consequently decides to continue cultivation of the crop at timet $=1$.

\section{Results and Discussion}

Figure 2 points out that 62.5 percent of the respondents indicated that flexibility in use was the major reason that drove them to adopting maize as the alternative to pearl millet. This is attributed to the fact that maize has more uses as compared to millet. Presence of a ready market for maize comprised 17.5 percent of the respondents while less demanding nature of the crop and convenience constituted 12.5 percent and 7.5 percent respectively. This indicates that the households have the perception that the higher the number of uses a crop has the more superior the crop is.

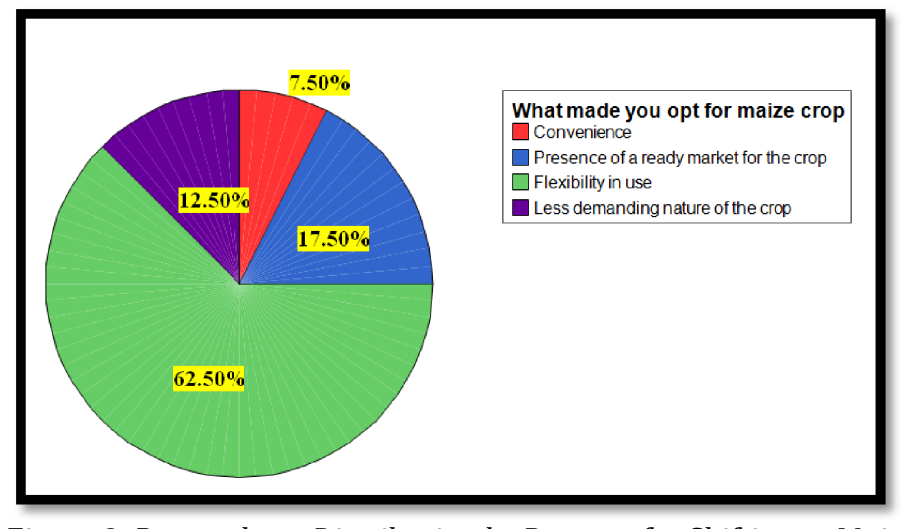

Figure 2: Respondents Distribution by Reasons for Shifting to Maize

Pearl millet was mainly abandoned due to its labor intensiveness attribute. The study results indicate that 95 percent of the respondents pointed out that they abandoned pearl millet because of its labor intensiveness particularly during its last phase of growth when birds invade pearl millet fields. Lack of credit services, cultural change, pearl millet characteristics and low prices each comprised of 1.3 percent of the respondents meaning they had equal influence on household's decision to abandon pearl millet. A study carried in Nzoia and Mumias sugar belt by Netondo et al, 2010 revealed that $4.8 \%$ of the respondents indicated that labor intensiveness was a contributory reason for opting to abandon some of their former traditional crops such as finger millet, simsim, sorgum and bambara. The study indicated that land fragmentation was the major reason for their decision to abandon indigenous crops in both nzoia and mumias sugarbelt with 34.5 and $34.9 \%$ of respondents respectively ascertaining this. However, reasons for deserting cultivation of food crops were varied. Whereas massive 89.4 percent respondents in Mumias pointed sugar cane farming as the main cause, only 26.7 percent respondents gave the same reason for Nzoia. However almost equal number of respondents attributed land fragmentation with percentages standing at 34.9 and 34.5 for Mumias and Nzoia, respectively. In Mumias 27.5 percent of the respondents indicated that soil infertility influenced their decision to abandoning food crops in Mumias, however this was not the case in Nzoia. Other reasons mentioned includes pests and diseases, change of taste and preference, low production, labor intensive, lack of seeds, lack of ready market, change of climate and low returns. Less than 10 percent of the respondents cited these reasons as cause for abandonment. The consequential effect of abandonment of food crops and vegetable cultivation is their observable disappearance in Mumias and Nzoia sugar belts and generally the Lake Victoria sugarcane-growing region. 


\begin{tabular}{|c|c|}
\hline Reason & Percentage of Respondents \\
\hline Labor intensiveness & 95 \\
\hline Lack of credit services & 1.25 \\
\hline Cultural change & 1.25 \\
\hline Pearl millet characteristics & 1.25 \\
\hline Low prices & 1.25 \\
\hline Reason & Percentage of Respondents \\
\hline Labor intensiveness & 95 \\
\hline Lack of credit services & 1.25 \\
\hline Cultural change & 1.25 \\
\hline Pearl millet characteristics & 1.25 \\
\hline Low prices & 1.25 \\
\hline
\end{tabular}

\subsection{Household's Gross Margins Characteristics}

The household's total gross margins summation for maize in Tigania west district amounts to a negative figure of KES 15,118 while that for pearl millet in Tharaka district amounts to a positive figure of KES 498,980. Farmers in Tigania west district do not consider their own labor as an input to which monetary value can be attached in production of maize and this is a contributory reason to their continued production of maize despite incurring losses. Only 2 percent and 0.5 percent of farmers in Tigania and Tharaka districts respectively account for their own labor in their gross margin analysis. For these farmers labor can only be monetized (accounted for) if it is hired. It is apparent from the figures that pearl millet is highly profitable as compared to maize.

\begin{tabular}{|c|c|c|}
\hline & Tigania West District (Maize) & Tharaka District (Pearl millet) \\
\hline Gross margin summation (KES) & $-15,118.00$ & $498,980.00$ \\
\hline Gross margin per acre (KES) & -189.00 & $6,237.00$ \\
\hline Std deviation & $7,365.00$ & $5,323.80$ \\
\hline Std error mean & 823.43 & 595.22 \\
\hline Own labor accounting & $2 \%$ & $0.50 \%$ \\
\hline
\end{tabular}

Table 2: Gross Margin Analysis (Tigania West District and Tharaka District)

Table 3 provides the actual results from the independent t-test and Levine's Test for Equality of Variances. Since we have a $P$-value of 0.063 from the result of Levine's Test we therefore conclude that we have equal variance for the gross margins in the two districts. Sig. (2-tailed) indicates the probability of error $(p)$, and Since the probability of error is $<.05$, we must reject the null hypothesis of no difference between mean gross margins and conclude that there is a significant difference between the mean gross margins of maize and pearl millet in Tigania west and Tharaka districts respectively.

\begin{tabular}{|c|c|c|c|c|c|c|}
\hline Levene's Test for Equality of Variances & \multicolumn{5}{|c|}{ T-Test for Equality of Means } \\
\hline F & Sig & t & Df & $\begin{array}{c}\text { Sig.(2- } \\
\text { tailed) }\end{array}$ & Mean Difference & Std. Error \\
\hline 3.515 & 0.063 & -6.325 & 160 & .000 & $-6,426.23$ & $1,016.03$ \\
\hline
\end{tabular}

Table 3: Independent Samples Gross Margin T-Test and Levene's Results

The study revealed that 44 percent of the interviewed farmers in Tigania west district recorded negative gross margins for maize in their farms and 56 percent had positive values for their maize gross margins as indicated in figure 5. This shows how badly maize as a crop performs in terms of productivity in Tigania west district, because the objective of any rational farmer is to maximize profit in his or her agricultural activities. 


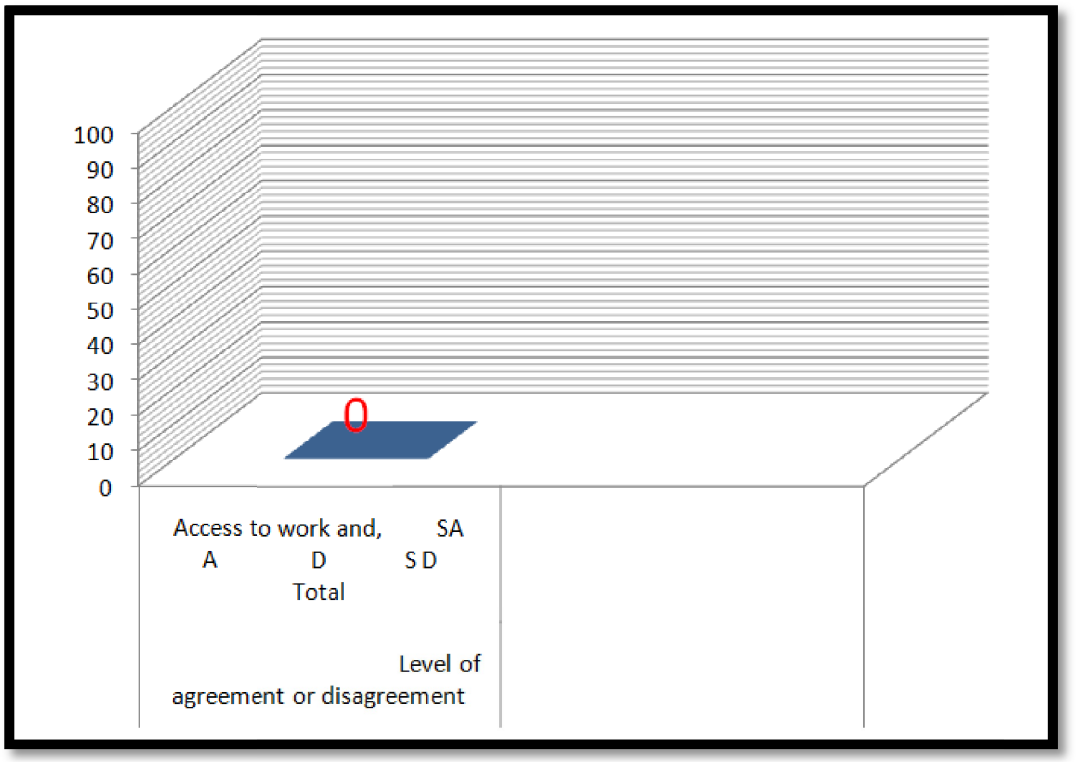

Figure 3: Maize Gross Margins for Tigania West District

Tharaka district performs better in terms of gross margin as a massive 98 percent of farmers interviewed in the district recorded positive values for their pearl millet gross margins. Only 2 percent of the interviewed farmers in the district had negative gross margins for pearl millet. This is an indicator of how suited pearl millet is in the district.

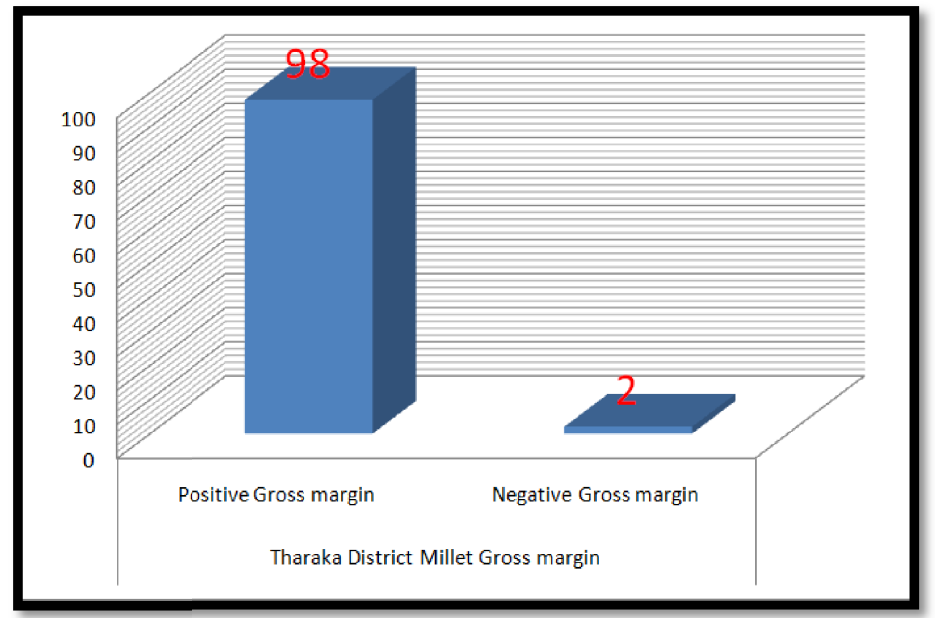

Figure 4: Tharaka District Pearl Millet Gross Margin

\section{Conclusion}

The study revealed that farmers in Tigania west district chose to abandon pearl millet cultivation because of its labor intensiveness and shifted to maize, because maize is considered a more flexible and multipurpose crop. Maize crop in Tigania west district performs dismally as study results indicate that 44 percent of maize farmers in the district experience negative gross margins for maize crop. In Tharaka district where farmers grow pearl millet as opposed to maize, have 98 percent of farmers obtaining positive gross margins for the crop. The mean gross margin for maize in Tigania west district is KES -189 while that for pearl millet in Tharaka district is KES 6,237. The two districts have similar biophysical conditions and the difference in mean gross margins largely results from the farmer's choice of enterprise.

Farmers in the two districts do not consider family labor as a constituent element in gross margin determination and this leads to inflated farm profits. This could be the reason why farmers in Tigania West district have continued with maize production despite incurring negative gross margins. Only 2 percent of the farmers indicated that they account for family labor in their enterprise gross margin determination in the district.

\section{References}

i. Babcock, B.A. and D.A. Hennessy. (1996). Input Demand under Yield and Revenue Insurance, American Journal of Agricultural Economics 78:416-427

ii. Chambers, Robert G. (1989). "Insurability and Moral Hazard in Agricultural Insurance Markets." American Journal of Agricultural Economics 71:604-616.

iii. Chambers, R.G. and J. Quiggin. (2002). “Optimal Producer Behavior in the Presence of Area-Yield Crop Insurance." 1 
iv. Coble, K.H., T.O. Knight, R.D. Pope, and J.R. Williams. (1997). "An Expected-Indemnity Approach to the Measurement of Moral Hazard in Crop Insurance." AmericanJournal of Agricultural Economics 79:216-226.

v. Food and Agriculture Organization. (1996). The world sorghum and millet economies: facts, trends and outlook. FAO Document Repository W1808/E. Www.ifad.org/grants

vi. Horowitz, J.K. and E. Lichtenberg. (1993). "Insurance, Moral Hazard, and Chemical Use in Agriculture." American Journal of Agricultural Economics 75:926-935.

vii. ICRISAT and FAO, The World Sorghum and Millet Economies. International CropsResearch Institute for the SemiArid Tropics, Patancheru, India. Food and Agriculture Organization of the United Nations, Rome, pp. 31-53 (1996).

viii. National Research Council. (1996). Lost crops of Africa. Volume I: Grains. National Academy Press. Washington DC.

ix. Netondo, G.W, Waswa, F, Maina, L., Naisiko, T., Masayi, N. and Ngaira, K. J "Agrobiodiversity endangered by sugarcane farming in Mumias and Nzoia Sugarbelts of Western Kenya." African Journal of Environmental Science and Technology Vol. 4(7), pp. 437-445, July 2010

x. Obilana A.B and Manyasa E, (2002) Millets, in Pseudocereals and less common cereals, ed. by Belton P.S and Taylor J.R.N, Springer-Verlag, Berlin.

xi. The Annual Report, Crop Development Division, Ministry of Agriculture, 2003

xii. The Syngenta Foundation for Sustainable Agriculture. (2002). Millet: Pearl Millet. http://syngentafoundation.org/what is pearl millet.htm

xiii. Vercammen, J. and G.C. van Kooten. 1994. "Moral Hazard Cycles in Individual-Coverage Crop Insurance." American Journal of Agricultural Economics 76:250-261. 